\title{
Development of Mathematics Interest in Adolescence: Influences of Gender, Family, and School Context
}

\author{
Anne C. Frenzel \\ University of Munich \\ Thomas Goetz
}

University of Konstanz and Thurgau University of Teacher Education

\author{
Reinhard Pekrun \\ University of Munich \\ Helen M. G. Watt \\ Monash University
}

\begin{abstract}
This study investigated adolescents' developmental trajectories of mathematics interest and explored related effects of gender, family, and school context. Latent growth curve modeling was used to analyze longitudinal data of $N \quad 3,193$ students (51\% female) from grades 5 to 9 from all 3 ability tracks of the German state school system. Annual assessments involved student ques tionnaires on interest in mathematics, perceptions of classroom characteristics (classroom values for mathematics, mathematics teacher enthusiasm), as well as parent questionnaires regarding family values for mathematics. Results indicated a downward trend of students' mathematics interest that plateaued in later years, with high variability in mean levels, but little variability in the shape of the growth trajectories. Boys reported higher mathematics interest than girls, but similar downward growth trajectories. Students from the lowest ability track showed more favorable interest trajectories than students from the middle and highest tracks. Family values and classroom characteristics were positively related to within person levels of interest over time and to average individual levels of interest, but not to growth parameters. Theoretical and practical implications are discussed.
\end{abstract}

Requests for reprints should be sent to Anne C. Frenzel, Department of Psychology, University of Munich, Leopoldstrasse 13, 80802 Muenchen, Germany. E mail: frenzel@psy.lmu.de 
We all know how powerful interest can be in guiding our behavior and making our choices. The desire to reengage in content over time, to seek answers to questions, to acquire more knowledge, and to understand better promotes achievement and excellence in education as well as professional careers. Interest is an important force determining the quality of learning (Baumert \& Schnabel, 1998; Schiefele, Krapp, \& Winteler, 1992) as well as educational and occupational choices (Nagy, Trautwein, Baumert, Köller, \& Garrett, 2006). Therefore, the lack of academic interest among many adolescent students is a major problem for educators (Hidi \& Harackiewicz, 2000). The domains of mathematics and science in particular seem to repel many students during adolescence (Hoffmann, Krapp, Renninger, \& Baumert, 1998; Kessels \& Hannover, 2007). Research has repeatedly shown downward developmental trends of mathematics interest during the course of secondary school (Eccles et al., 1983; Fredricks \& Eccles, 2002; Jacobs, Lanza, Osgood, Eccles, \& Wigfield, 2002; Köller, Baumert, \& Schnabel, 2001; Watt, 2004).

Another consistent finding in the literature on mathematics interest is the effect of gender; a number of studies have documented that boys are more interested in mathematics than girls (Eccles et al., 1983; Fredricks \& Eccles, 2002; Hoffmann et al., 1998; Jacobs et al., 2002; OECD, 2004; Watt, 2004). Mathematics thus still seems to be considered a male domain (Hyde, Fennema, Ryan, Frost, \& Hopp, 1990; Kessels \& Hannover, 2007), and girls, even more so than boys, seem to have an aversion to this domain. The consistent decline and the gender differences in mathematics interest during adolescence are of practical relevance. There is a need to catch and hold students' interest in mathematics, to tap the full potential of talents within this domain-both male and female-and to encourage them to pursue related careers. Expertise in mathematics is a necessary condition for important advances in our society, for example, in engineering and information technologies (Watt, Richardson, \& Pietsch, 2009).

The present research is grounded in a social-cognitive perspective. From such a perspective, parents, peers, and teachers are of primary importance for the formation of self- and task-related beliefs and values pertaining to different domains (e.g., Eccles et al., 1983; Pekrun, 2000). We expected that value-nurturing contexts provided by parents who highly value mathematics, classmates who appreciate the subject, and mathematics teachers who enthusiastically transmit the attractiveness of mathematics should relate positively to students' interest in mathematics.

The study is based on a German longitudinal data set of $>3,000$ students from grades 5 through 9 and was designed to focus specifically on mathematics interest. There are overlaps in the ages studied compared with existing longitudinal studies from the United States and Australia (Fredricks \& Eccles, 2002; Jacobs et al., 2002; Watt, 2004), but the present study differs in terms of institutional setting. The German school system is strictly 
ability-group differentiated, and students are streamed into three different school tracks after the 4th grade based on their prior school achievement. There is no additional school transition after grade 4 .

The overarching goal of the present study was thus to analyze developmental trajectories of mathematics interest and related effects of gender in this context. In addition, the present study goes beyond the existing studies by considering major contextual school and family factors and their relationships to the development of adolescents' mathematics interest. The factors we consider are school track and teacher enthusiasm as well as parental and classroom values for mathematics.

\section{THE CONSTRUCT OF INTEREST}

Contemporary approaches define interest as a motivational variable that refers to an individual's engagement with particular classes of objects and activities. Three important characteristics of the construct have been identified. First, it has both a state and a trait character. Many researchers (e.g., Hidi, 1990; Krapp, 2000; Renninger, 2000; Schiefele, 1991) differentiate between situationally triggered interest in a particular topic at a given moment (situational interest) and habitualized personal interest that someone has in a topic or activity (individual interest). While situational interest can fluctuate from moment to moment, individual interest typically remains more or less stable over time, although it can obviously change over longer periods. In our study, we focus on adolescents' individual interest in mathematics.

Second, interest is generally seen as being content-specific (e.g., Hidi \& Renninger, 2006; Krapp, 2000; Schiefele, 1991). That is, there is no such thing as general student interest-a student may be highly interested in literature, but not in mathematics, or vice versa. By implication, any scientific inquiry into the topic of interest should adopt a domain-specific approach. In the present study, we focus on the domain of mathematics.

Third, the construct of interest is conceptually very close to those of values and enjoyment. Interest-triggered actions are characterized by the enjoyment one experiences while engaging in them, paired with a conviction of the personal significance of the action (Krapp, 2000; Renninger, 2000; Schiefele, 1991). Conceptual closeness among constructs is also expressed in the fact that in Eccles and colleagues' theory of subjective values (Eccles et al., 1983; Wigfield \& Eccles, 1992), one of the value components (intrinsic value) is usually defined as the enjoyment one gets from carrying out a task. In some of her research (e.g., Fredricks \& Eccles, 2002), this value component is also referred to as interest. Given these conceptual overlaps we include in our review the bodies of literature on values and enjoyment to infer our hypotheses regarding the development of mathematics interest during adolescence. 


\section{INTEREST IN MATHEMATICS: DEVELOPMENTAL TRENDS}

Theoretical deliberations about interest development proposed by Schiefele (2001), Krapp (2000), Hidi (2000), Baumert and Köller (1998), and Todt and Schreiber (1998) concur in predicting interest declines from childhood through to adulthood. These theorists all seem to agree that interest develops from a universal curiosity and boundless energy to explore and learn new skills in childhood, to select preferences of certain fields. Interest losses have been explained by factors inherent in age-related changes, such as increased task complexity, demands for effort, and a resultant lack of the intrinsic attractiveness of academic contents (Hidi, 2000; Zimmerman \& Kitsantas, 1999) as well as changes in social relationships during adolescence (Hidi, 2000) that bring about a decrease in academic interests as a response to increasing social interests. Some researchers suggested that interest losses can also be attributed to an institutionalized mismatch between students' rising desire for self-determination and the increasingly restrictive learning environment as they progress through school, particularly at transitions to junior and middle high schools (Eccles et al., 1991; Eccles \& Midgley, 1989; Eccles et al., 1993).

Regarding the empirical evidence for developmental trends in mathematics interest in particular, a number of studies have analyzed the development of students' ability-related beliefs in mathematics, but relatively few studies have been conducted with a focus on mathematics interest. Köller et al. (2001) longitudinally analyzed mathematics interest in students from German high-ability track schools (Gymnasium) at three time points (end of grade 7 , end of grade 10, and middle of grade 12). Based on repeatedmeasures ANOVAs, they reported consistent downward trends of interest in mathematics during that period. Furthermore, Eccles, Wigfield, and colleagues conducted studies regarding the development of mathematics values during the 1980s and 1990s. They have consistently found a decline in intrinsic mathematics values across the transition to junior high school and into the high school years (Eccles et al., 1983, 1989; Eccles, Adler, \& Meece, 1984; Wigfield, Eccles, Mac Iver, Reuman, \& Midgley, 1991).

Finally, three recent large-scale American and Australian longitudinal studies have provided findings on the development of adolescents' mathrelated values (Fredricks \& Eccles, 2002; Jacobs et al., 2002; Watt, 2004). Their results pertaining to the development of intrinsic values are of primary interest for our present investigation. Using latent growth curve modeling, these authors reported curvilinear declines of intrinsic mathematics values, which were more pronounced in earlier years and then plateaued in senior years. Smooth quadratic growth trajectories fitted these declines well, even in the U.S. data set, which involved two school transitions during the observed time period, suggesting that those transitions did not dramatically affect values development. Nevertheless, 
Jacobs et al. (2002) attributed some of the declines to transition-related changes in school environments.

\section{INTEREST IN MATHEMATICS: GENDER DIFFERENCES}

Eccles, Wigfield, Harold, and Blumenfeld (1993) and Wigfield et al. (1997) could not detect any gender differences in generalized mathematics values among primary school children. However, for mathematics enjoyment, consistent gender differences have been documented as early as grades 3 and 4 (Lichtenfeld, Frenzel, \& Pekrun, 2007) and grade 5 (Frenzel, Pekrun, \& Goetz, 2007a). Several other studies have found that by adolescence, boys have systematically higher scores on intrinsic values (see the meta-analysis on gender comparisons in mathematics affect by Hyde et al., 1990). In Köller et al.'s (2001) study involving German students in the upper secondary years, boys showed a higher level of interest in mathematics than girls. Finally, in the 2003 assessment of the OECD "Programme of International Student Assessment," which focused on mathematics, there were consistent gender differences in a composite measure of mathematics interest and enjoyment among the 15-year-old participants across all 41 participating countries (OECD, 2004).

The smaller size or even absence of gender differences in mathematics interest and values in primary school coupled with pronounced differences at later ages seems to imply that gender differences in mathematics interest intensify from elementary school to middle and junior high school. Genderrole socialization has been offered as an explanation (e.g., Eccles, 1987; Galambos, Almeida, \& Peterson, 1990; Hill \& Lynch, 1983). However, within the recent longitudinal studies on mathematics values, Jacobs et al. (2002), Fredricks and Eccles (2002), and Watt (2004) detected gender differences in levels, but not more unfavorably curved trajectories of mathematics values between girls and boys. In conclusion, the authors of these studies have argued that the empirical evidence for a gender intensification hypothesis is weak. Consequently, we expected that girls' and boys' mathematics interests would develop on different levels, but along similarly shaped growth trajectories during adolescence.

\section{ABILITY GROUPING AND INTEREST DEVELOPMENT}

Ability grouping is discussed controversially (LeTendre, Hofer, \& Shimizu, 2003; Lucas, 1999). Its aim is to provide classroom instruction tailored to students' abilities to optimize cognitive learning outcomes for each student. However, regarding affective learning outcomes, there is in fact cumulative evidence of negative effects of being placed in high-achievement groups and positive effects of being placed in low-achievement groups, particularly for academic self-concepts. Favorable upward and unfavorable downward 
social comparisons as a result of being streamed into ability groups have been proposed as the explanation for this phenomenon, typically referred to as the "Big Fish Little Pond Effect" (BFLPE; Marsh, 1987).

The vast majority of studies on the BFLPE pertain to the construct of domain-specific self-concepts, but there is also evidence that other affectivemotivational variables comply with this pattern, including enjoyment, anxiety, and educational aspirations (Goetz et al., 2004; Marsh, 1991; Zeidner, 1998). Regarding mathematics interest in particular, a recent study by Trautwein, Lüdtke, Marsh, Köller, and Baumert (2006) showed that German ninth-grade students' mathematics interest differed as a function of ability group, with students from the Hauptschule (lowest track) reporting the highest and students from the Gymnasium (highest track) the lowest mean levels of mathematics interest. The authors speculated that their findings imply that "students are less likely to develop high personal interest in mathematics when placed in a high-achieving track" (p. 803). However, no study to date seems to have analyzed the impact of ability grouping on interest development using a long-term longitudinal design. Modeling these effects was an important goal of the present study.

\section{FAMILY AND CLASSROOM CONTEXTS AND INTEREST DEVELOPMENT}

Social-cognitive theorists agree that learning and development involves a permanent interchange between a person and his or her social environment. Typically, parents, peers, and teachers are considered to contribute to children's and adolescents' development of self- and task-related beliefs, and also to their interests. In his social-cognitive approach to achievement emotions, Pekrun (2000) uses the term "value induction" (p. 157). He argues that value transmission may work via direct verbal information or by behavioral modeling (when values are conveyed by the behavior of significant others and then adopted by the students). Similarly, Eccles et al. (1993) have argued that social contextual influences on the ontogeny of academic values work via parents and teachers as "interpreters of reality" (pp. 154, 177) and by "provision of experience" (p. 169).

\section{Family}

Numerous studies have linked parenting practices to children's achievement motivation. It has often been argued that parents act as role models and expectancy socializers for their children. For example, Jacobs, DavisKean, Bleeker, Eccles, and Malanchuk (2005) and Jacobs and Eccles (2000) argued that parents influence their children by modeling involvement in valued activities. Thus, since parents are powerful role models for their 
children, students are most likely to value what their parents value (Eccles, Adler, \& Kaczala, 1982; Eccles et al., 1993; Whitbeck \& Gecas, 1988). In addition, when parents show interest and enthusiasm for a particular subject or domain, they provide a support system at home that should buttress a child's own value of the subject (Eccles et al., 1993; Gonzalez-DeHass, Willems, \& Holbein, 2005).

While there are numerous studies about the relationship between parental expectations and student motivation as well as achievement, only very few studies explicitly address family values relating to academic tasks or activities (see also Jacobs et al., 2005), and yet fewer address the relationship between family values and student interest in specific school subjects. In one study exploring the relationship between parents' and students' academic values in general, Marchant, Paulson, and Rothlisberg (2001) found that the correlation between students' perceptions of their parents' academic values and their own ratings of the importance of ability, effort, and grades was $r=.48$. However, after removing the common method bias (which is present when both parental and student values are assessed as perceived by the students) by relating parent-related values with student-reported values, correlations typically are lower, ranging between $r=.20$ and .30 (Whitbeck \& Gecas, 1988). Using such a multiple-perspectives approach and exploring values in the domain of mathematics, Eccles et al. (1982) found that parents' beliefs about the importance of mathematics for their 5th through 12th grade children were significantly positively related to the students' own values of mathematics (with typical magnitude of $r=.30$ ). In addition, Eccles et al. (1983) found that parents' perceptions of the importance of mathematics and student valuing of mathematics were positively related, and that this relationship was mediated by the students' perceptions of their parents' aspirations for them. Our present study also followed a multiple-perspective approach by incorporating parents' reports of mathematics value and exploring how these relate to students' interest in mathematics.

\section{Classmates}

Individuation and acquisition of autonomy during adolescence is characterized by less time spent with parents and family and more time spent with peers (Larson \& Richards, 1991). Therefore, in the adolescent years, the strong influence that parents exert on their children's value formation is increasingly expanded and challenged by peer influences (Brown, 1990; Kindermann, 1993).

In the German school system, students stay with the same group of students across most subjects within a school year. Therefore, classmates can be assumed to play an important role for the formation of German students' achievement-related beliefs and values, even if these classmates do not always correspond with the peer group of leisure-time friends. In a 
cross-sectional study relating aspects of classroom climate to student enjoyment in mathematics, Frenzel, Pekrun, and Goetz (2007b) reported that classaggregated student perceptions of classroom values for mathematics were significantly positively related to students' mathematics enjoyment. In the present study, we examined the impact of class-aggregated perceived classroom mathematics values averaged across several consecutive school years on the development of students' mathematics interest. We thus extend existing research regarding peer influences on interest, providing a longitudinal perspective and substantiating empirical findings for the domain of mathematics in particular.

\section{Teachers}

Regarding effects of teachers on students' interest development, our question is, can teachers pique students' interest in a subject or undermine the interests that the students initially had? A number of classroom practices have been identified as undermining the interest and value students attach to mathematics and science, such as the use of competitive, public motivational strategies, frequent use of public drill and practice, and insincere use of praise and criticism (e.g., Flink, Boggiano, \& Barrett, 1990; Turner et al., 2002). On the other hand, frequent use of hands-on learning opportunities and applied problem-solving tasks have been reported to facilitate students' interest (Bergin, 1999; Wigfield \& Eccles, 1992). In addition, teacher attitudes and enthusiasm likely are related to students' interest development (e.g., Eccles et al., 1993). In research on teacher enthusiasm, a few studies have shown that there is a positive relationship between teachers' verbal and nonverbal messages about the value of learning material, on the one hand, and students' interest and intrinsic motivation, on the other hand (Brigham, Scruggs, \& Mastropieri, 1992; McKinney, Robertson, Gilmore, Ford, \& Larkins, 1984; Patrick, Hisley, Kempler, \& College, 2000).

\section{RESEARCH QUESTIONS AND HYPOTHESES OF THE PRESENT STUDY}

Using a longitudinal design, the present study was designed to answer the following research questions.

(1) How does mathematics interest develop in adolescence from grades 5 to 9 ? Based on the existing empirical evidence and on theoretical deliberations concerning the stabilization of interests in adolescence, we expected a quadratic growth trajectory characterized by more pronounced losses in the lower grades and a leveling out of interest declines in higher grades. 
(2) Are there gender differences in levels and trajectories of mathematics interest? We expected that there would be gender differences in the level of interest in mathematics throughout adolescence. However, given the weak empirical support for gender intensification reported in the literature, we did not expect effects of gender on the growth parameters for interest trajectories.

(3) How is membership in different ability groups (lowest, middle, and highest track in the German threefold school system) related to mathematics interest development during adolescence? As noted, there is consistent evidence regarding the BFLPE on self-concept. We proposed that ability grouping should also have an impact on the development of students' mathematics interest during adolescence. Specifically, we expected that interest trajectories should be more favorable for lower ability tracks (i.e., they should show weaker declines and wider curvature in interest trajectories).

(4) How do the mathematics values held by significant others (family, classmates, teachers) relate to mathematics interest? We expected positive within-student relationships of these values with students' levels of interest experienced in different grades. In addition, we expected that students who were exposed to higher parental values, classroom values, and teacher enthusiasm over time would show higher overall levels of interest, and speculated they may show more favorable interest trajectories.

\section{METHOD}

\section{Sample and Procedures}

Data from $N=3,193$ students (51\% female) were included in our analyses. These data were from a large-scale longitudinal study spanning grades 5 through 9, examining student mathematics learning (Project for the Analysis of Learning and Achievement in Mathematics [PALMA]; see Pekrun et al., 2007). The German Data Processing Center of the International Association for the Evaluation of Educational Achievement was responsible for drawing the student sample and organizing assessments. The PALMA sample can be considered representative of the Bavarian student population, with students coming from a wide range of socioeconomic backgrounds and from each of the three school tracks of the German state school system (see Pekrun et al., 2007, for a detailed description of the study).

The sample included $N=1,144$ students from the Hauptschule, $N=926$ students from the Realschule, and $N=1,123$ students from the Gymnasium. In the threefold school system predominant in Germany, the school type with the lowest academic demands is the Hauptschule, which is primarily vocationally oriented. The Realschule offers a curriculum of 
general education also laying the foundation for a future vocational career, but provides better opportunities for acquiring higher educational qualifications. The Gymnasium involves the highest academic demands. Passing the final examination of the Gymnasium (the "Abitur") entitles students to study at university level. Allocation to these tracks is based on academic achievement in grade 4, but parents also have a say in deciding about school track attendance. Since both grade 4 achievement and parents' educational aspirations are related to student socioeconomic status, track attendance is closely related to SES in the German school system (Schnepf, 2003).

In the PALMA longitudinal study, intact classrooms were sampled in grade 5 and followed in annual assessments over the subsequent school years. Initially, in 5th grade, 83 classes from 42 schools were sampled (typically two classes per school). All schools and classes who were invited to participate agreed to do so. Across annual assessments, the progression of intact classes was monitored. Whenever class composition was reorganized across time (e.g., because students are offered subject choices through their scholastic career, such as regarding foreign languages), those classrooms that were constituted by the majority of students from the initial classrooms were followed. Students who had not yet participated in the study but who became members of PALMA classrooms were added to the sample. In addition, if students no longer attended the longitudinally followed intact classrooms, they were dropped from the sample. Despite student dropout due to class recompositions or study attrition, the number of students participating thus increased rather than decreased in most of the years, and our analyses were based on a balanced average number of $24.4 / 24.6 / 24.4 / 23.8$ / 23.1 students per class in grades $5 / 6 / 7 / 8 / 9$, respectively. This completeclass sampling strategy meant that class-average judgments were available as meaningful measures of instructional and classroom climate (see Aleamoni, 1999; De Jong \& Westerhof, 2001, for the quality of aggregated student ratings as an indicator of instructional and climate measures). In the present study, we utilized class-average data regarding classroom values for mathematics and teacher enthusiasm. Table 1 describes the rates and patterns of participation across successive occasions. Missing values analysis confirmed that mathematics interest was not related to attrition at any time point.

PALMA involved the annual administration of student and parent surveys at the end of each academic year (in May) assessing several constructs, including students' and their parents' beliefs and values pertaining to learning mathematics and the students' perceptions of their classroom climate and their mathematics teachers' instructional behavior. Parental permission was needed for students to participate, solicited at the first administration. Parental consent rates were very high (average 97\% across years); parental survey participation rates were somewhat lower (average $86 \%$ across years). 
TABLE 1

Participation Rates and Missing Data Patterns

\begin{tabular}{|c|c|c|}
\hline & $N$ & $\%$ girls \\
\hline \multicolumn{3}{|c|}{ \# of students participating } \\
\hline In grade 5 & 2,023 & 50.0 \\
\hline In grade 6 & 2,016 & 50.4 \\
\hline In grade 7 & 2,302 & 49.1 \\
\hline In grade 8 & 2,308 & 51.1 \\
\hline In grade 9 & 2,377 & 51.8 \\
\hline At least once & 3,193 & 51.0 \\
\hline At least twice & 2,564 & 49.4 \\
\hline At least three times & 1,670 & 49.8 \\
\hline At least four times & 1,079 & 50.1 \\
\hline Five times & 776 & 52.2 \\
\hline \multicolumn{3}{|c|}{$\begin{array}{l}\text { Patterns of participation across the five occasions } \\
\quad \text { (1 participated/0 missing) }\end{array}$} \\
\hline 00001 & 215 & 54.0 \\
\hline 00010 & 37 & 45.9 \\
\hline 00011 & 130 & 53.1 \\
\hline 00100 & 64 & 45.3 \\
\hline 00101 & 9 & 77.8 \\
\hline 00110 & 75 & 46.7 \\
\hline 00111 & 419 & 53.0 \\
\hline 01000 & 80 & 45.0 \\
\hline 01001 & 1 & 100.0 \\
\hline 01010 & 2 & 50.0 \\
\hline 01011 & 5 & 80.0 \\
\hline 01100 & 19 & 57.9 \\
\hline 01101 & 5 & 100.0 \\
\hline 01110 & 20 & 50.0 \\
\hline 01111 & 89 & 58.4 \\
\hline 10000 & 233 & 48.5 \\
\hline 10011 & 1 & 100.0 \\
\hline 10110 & 3 & 33.3 \\
\hline 10111 & 16 & 68.8 \\
\hline 11000 & 658 & 49.1 \\
\hline 11001 & 12 & 16.7 \\
\hline 11010 & 1 & 0.0 \\
\hline 11011 & 15 & 60.0 \\
\hline 11100 & 125 & 45.6 \\
\hline 11101 & 14 & 50.0 \\
\hline 11110 & 169 & 49.1 \\
\hline 11111 & 776 & 52.2 \\
\hline
\end{tabular}




\section{Measures}

Identical items were used each year to assess the study constructs. Responses were scored using 5-point Likert agreement scales ranging from $1=$ strongly disagree to 5 strongly agree. Scale scores were produced by averaging the respondents' answers to all items comprising each scale.

Mathematics interest. Student mathematics interest was assessed with six items (see Appendix A for item wordings translated to English for this article). Items from the "Questionnaire for Study Interest" (Schiefele, Krapp, Wild, \& Winteler, 1993) were adapted to refer specifically to the subject of mathematics and to suit the target group of adolescent students. The scale assessed personal interest in the subject of mathematics, tapping both cognitive and affective components of the construct. It was highly internally consistent across the entire survey period (Cronbach's $\alpha$ was $.87 / .88 / .86 /$ $.88 / .88$ in grades $5 / 6 / 7 / 8 / 9$, respectively). Evidence for construct validity comes from its consistent positive relationships with students' enjoyment of mathematics, as assessed with the Academic Emotions QuestionnaireMathematics (Pekrun, Goetz, \& Frenzel, 2005). Table 2 presents means, standard deviations and stability across consecutive measurement occasions for student interest.

Family values for mathematics. Parents were asked to rate the value of mathematics held in the family with six items (e.g., "We consider mathematics as very important"; "In our home, we often engage with topics relating to mathematics because we are interested in this domain"). This scale was developed specifically for the PALMA study. The validity of the scale is supported by consistent relationships with student perceptions of family values, enjoyment, and effort in mathematics (Jullien, 2006; Pekrun et al., 2006). Parents provided internally consistent answers to these items across the survey period (Cronbach's $\alpha$ was $.80 / .81 / .82 / .83 / .84$ in grades 5/ $6 / 7 / 8 / 9$, respectively). Father / mother judgments were not distinguished in this study. Parents were rather encouraged to fill in the questionnaire together and to answer the items according to the "common atmosphere" in the family (see Table 2 for descriptive statistics). In the hierarchical linear modeling (HLM) analyses, family values were added both as time-varying covariates at level 1 and as predictors at the person level 2, using the individual scores for family values averaged across all time points at which the student had participated.

Classroom value for mathematics. Three items were used to assess students' perceptions of their classmates' value of mathematics ("Most of the students in this class find that math is cool," "Most of the students in this class think that math is a worthwhile subject," "Most of the students in this 


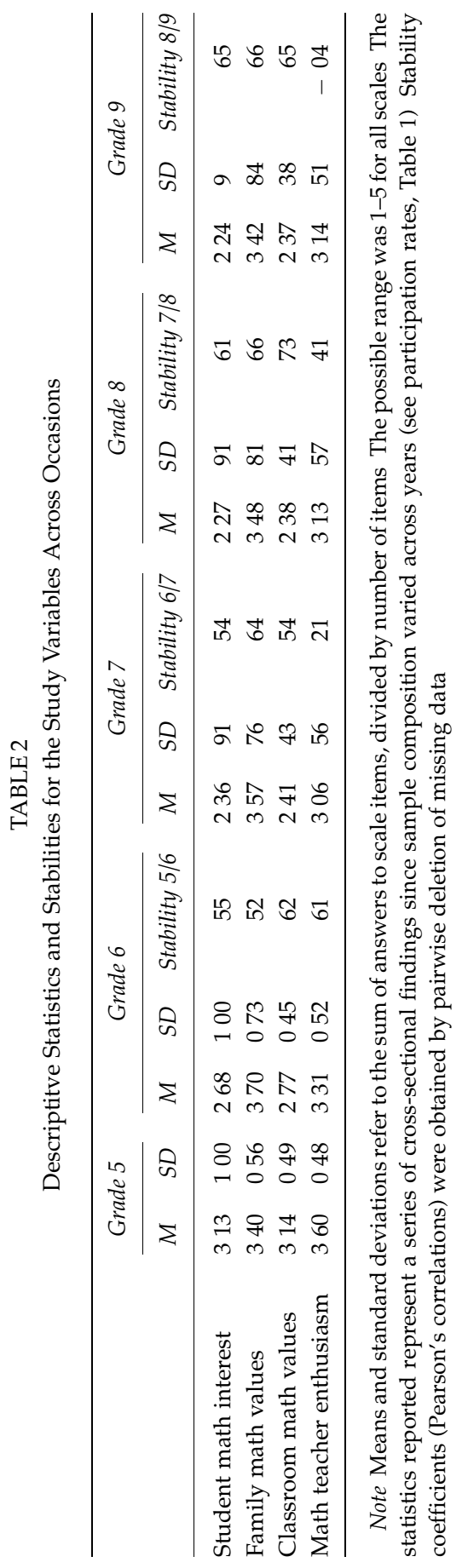


class think that learning math is fun"). This scale was developed specifically for the PALMA study. In cross-sectional analyses, class mean scores of classroom value for mathematics as measured with this scale have been shown to relate positively to student enjoyment in mathematics (Frenzel et al., 2007b; Pekrun et al., 2006). Class mean scores of this scale were included in the present analyses. Classes systematically differed in the degree to which they valued mathematics, as indicated by relatively high intraclass correlations (ICCs). The ICC(1) was .15/.12/.15/.14/.14 in grades $5 / 6 / 7 / 8 / 9$, respectively. We further used the corresponding ICC(2) to evaluate the reliability of the aggregated student ratings regarding the value of mathematics at the class level across the years (for the use of ICC(2) as a reliability indicator of classaggregated values see, e.g., Lüdtke, Trautwein, Kunter, \& Baumert, 2006). The ICC(2) was consistently satisfactory, $.82 / .77 / .81 / .80 / .78$ in grades $5 / 6 / 7 / 8 / 9$, respectively. Descriptive statistics are presented in Table 2 . In the analyses, this variable was added both as a time-varying covariate at level 1 and as a predictor at the person level 2, based on average class-mean scores across all time points at which the student had participated.

Mathematics teacher enthusiasm. Student perceptions of their mathematics teachers' enthusiasm during teaching were assessed with five items (e.g., "Our mathematics teacher tries to get the students excited about the subject of mathematics during instruction," "Our teacher really seems to enjoy teaching mathematics"). Item formulations were based on existing scales from teaching evaluation studies (Jackson et al., 1999; Marsh, 1982). Confirming the validity of this scale, scores were consistently positively related to student enjoyment of mathematics, and class-aggregated scores were positively related to teachers' own ratings of teaching enjoyment in class (Frenzel, Goetz, Lüdtke, Pekrun, \& Sutton, 2009). In the present study, class mean values of these scales were included (see Table 2 for descriptive statistics). Students within classes showed a considerable degree of homogeneity in their perceptions of their mathematics teachers' enthusiasm, as indicated by high ICCs. The ICC(1) was .19/.22/.25/.30/ .23 in grades $5 / 6 / 7 / 8 / 9$, respectively. The ICC(2) for aggregated perceptions of teacher enthusiasm was consistently satisfactory with $.85 / .88 / .89 / .91 / .88$ in grades $5 / 6 / 7 / 8 / 9$, respectively. These classroom mean values of teacher enthusiasm were again entered in the analyses both as time-varying covariates at level 1 and as person-level predictors at level 2, using average class-mean scores across all time points at which the student had participated.

\section{Strategy of Data Analysis: Latent Growth Curve Modeling With HLM}

We used the software HLM 6.04 for our analyses (Raudenbush, Bryk, \& Congdon, 2007). In the HLM approach, change phenomena can be 
represented through two-level hierarchical models. To describe the development of a criterion (in our case, interest) across time, a level- 1 model is constructed in which each person's development is represented by an individual growth trajectory that depends on a unique set of parameters. These parameters pertain to the shape of the growth curve as well as to predictor variables, which may also change across time (time-varying covariates; in the present study family values, classroom values, and teacher enthusiasm). The individual growth parameters can in turn be modeled as outcome variables in a level-2 model, where they are regressed on some (time-invariant) personlevel characteristics (in the present study, gender, school track, as well as family values for mathematics, classroom values for mathematics, and mathematics teacher enthusiasm averaged across assessments). ${ }^{1}$

HLM permits the inclusion of all respondents, even if they have not participated at all of the assessments included in the growth models, based on the "MAR" missing at random assumption (see Table 1 for participation rates in the present study), by applying the "full-information maximum-likelihood" method (Schafer \& Graham, 2002). This approach has the important advantage of providing results that better represent the entire sample, rather than just the subsample of students who have no missing data, while still providing appropriate tests of statistical significance to reflect the amount of missing data. It allows an integration of parameter estimation and handling of missing data in a single step that provides appropriate parameter estimates and standard errors (e.g., Allison, 2001). HLM represents a considerable advance over conventional change models (such as ANOVA) since it allows the researcher to model nonlinear growth, introduce predictors of the growth parameters, and accommodate missing data at individual points of measurement.

In the first step of the HLM analyses, the most suitable shape for the polynomial growth function to describe the interest growth trajectory was determined. This was done by consecutively adding higher-order polynomial parameters (linear, quadratic, cubic, etc.) until the beta weight for the fixed parameter of the highest polynomial predictor no longer proved to be significant (implying that no more significant proportions of within-person variance could be explained by increasing the polynomial degree of the growth function). This polynomial predictor was then discarded. Time was coded such that the mid-point of the series of assessments from grades 5 to 9 represented the reference category (with the linear change parameter assuming values of $-2,-1,0,1$, and 2 ; the quadratic values of $4,1,0,1,4$; the

\footnotetext{
${ }^{1}$ It is worth noting that our data even had a three rather than a two level structure, since in addition to time points nested within students, students also were nested within classrooms. However, since there were numerous occurrences of class recomposition across time, class mem bership was not time invariant, which is why this part of the hierarchical structure could not be modeled. As a result, standard errors for the effects on growth parameters may be underestimated in our analyses, and small effects should therefore be interpreted with caution.
} 
cubic values of $-8,-1,0,1,8$, etc.). The coding of time has implications for the interpretation of the corresponding parameters (Biesanz, Deeb-Sossa, Papadakis, Bollen, \& Curran, 2004; Raudenbush \& Bryk, 2002). Given a quadratic trajectory (which we expected), the different growth parameters can be interpreted as follows with our chosen coding of time: (1) the intercept represents the mean value of interest at grade $7 ;(2)$ the coefficient of the linear change represents the slope of the curvilinear trajectories at grade 7; and (3) the coefficient of the quadratic change represents the curvature of the parabolic function (this applies to any point of time; see Aiken \& West, 1991; Cohen, 1978). Each of the growth parameters was entered as both fixed and random effects, thus assuming that each student may follow individual change patterns.

Having identified the most suitable polynomial function describing the data, predictors were entered to explain the different growth coefficients. Applying the HLM notation, the resulting equations were as follows:

Level 1:

Student Mathematics Interest ${ }_{i j}=\pi_{0 j}+\pi_{1 j} \times$ time $+\pi_{2 j} \times($ time $)+$ error $_{i j}$ Level 2:

$$
\begin{aligned}
& \pi_{0 j}(\text { Intercept })=\beta_{00}+\beta_{01} \times \text { predictor }(\text { e.g., gender })+\text { error }_{0 j} \\
& \pi_{1 j}(\text { Linear slope })=\beta_{10}+\beta_{11} \times \text { predictor }(\text { e.g., gender })+\text { error }_{1 j} \\
& \pi_{2 j}(\text { Quadratic slope })=\beta_{20}+\beta_{21} \times \text { predictor }(\text { e.g., gender })+\text { error }_{2 j}
\end{aligned}
$$

It is important to state that care must be taken in interpreting the coefficients of the predictors since they also depend on the coding of time (Biesanz et al., 2004). For example, given our coding of time, a positive effect of gender (coded 0 for girls, 1 for boys) on the intercept and the slope would imply higher values and weaker declines for boys only at grade 7 . For example, if the latent male and female growth trajectories were to intersect, this effect could be completely different at other points in time. Only effects on the highest polynomial degree (in our case, quadratic growth) can be interpreted independently of how time is coded (Aiken \& West, 1991; Cohen, 1978). Therefore, a combination of a visual inspection of the estimated growth trajectories and an inspection of the fixed and random effects in the HLM models is imperative for meaningful interpretations (Biesanz et al., 2004).

\section{RESULTS}

This study was designed to explore trajectories of students' mathematics interest from grades 5 to 9 and analyze relationships with gender and contextual school and family factors. Below, the results of four HLM models are presented: a first model that assesses the shape of the growth function for 
student interest and three further models in which gender, school type, and the socializers' values were added consecutively.

\section{Development of Interest Over Time}

As a preliminary analysis step, we ran a null model without any predictors to decompose the total variability in interest scores for all students across all time points into within-student and between-student variance components (Raudenbush \& Bryk, 2002). This null model revealed that $49.3 \%$ of the variability lay within students and $50.7 \%$ between students. By implication, despite considerable developmental dynamics in adolescents' interest over time, a trait conceptualization of mathematics interest is warranted, given that half of the variability lay between different students.

The shape of the function that best described interest development is indicated by the first model (Basic Model, see first column in Table 3). A quadratic change trajectory appeared most suitable to describe average interest development: The fixed linear and quadratic growth parameters were significant, whereas the fixed parameter of the cubic growth was nonsignificant and therefore discarded from further analyses. The intercept expressing average levels of interest in grade 7 was 2.38 (on the scale from 1 to 5). The linear coefficient indicated that students lost interest at a rate of -.21 scale points at grade 7 . The quadratic coefficient of .08 indicated that the development of interest followed a positive, very wide parabola. This can be interpreted such that interest first considerably decreased and then plateaued during the time period observed in our study.

The random components of the model provide information regarding whether the growth parameters, that is, location and shape of the parabolic growth function, varied between students. As can be seen in the lower part of Table 3, there was considerable variability in the intercept (with a variance of .542 in grade 7) and in the linear portion of the trajectory (with a variance of .036 in grade 7 ), while the variability of the quadratic portion of the trajectory was just at the cut-off value for significance (with a variance of .003, $p=.05$ ). This implied that there was considerable variability in the location of the interest growth trajectory across students and comparatively little variability in its curvature.

\section{Gender}

The Gender Model (second column in Table 3) assessed the ways in which gender affected the growth parameters. First of all, a positive effect of gender on the intercept of .38 implied that boys were more interested in mathematics than girls at grade 7 (since gender was coded 0 for girls, 1 for boys), and a visual inspection of the different growth trajectories for girls and boys (see 
TABLE 3

Latent Growth Curve Models for the Development of Mathematics Interest From Grades 5 to 9

\begin{tabular}{|c|c|c|c|c|c|c|c|c|}
\hline & \multicolumn{2}{|c|}{ Basic Model } & \multicolumn{2}{|c|}{ Gender Model } & \multicolumn{2}{|c|}{$\begin{array}{c}\text { Gender + School } \\
\text { Track Model }\end{array}$} & \multicolumn{2}{|c|}{ Full Model } \\
\hline & $b$ & $S E$ & $b$ & $S E$ & $b$ & $S E$ & $b$ & $S E$ \\
\hline \multicolumn{9}{|l|}{ Fixed effects } \\
\hline Family values & & & & & & & $0.10 * *$ & .02 \\
\hline Classroom values & & & & & & & $0.33^{* * *}$ & .04 \\
\hline Teacher enthusiasm & & & & & & & $0.06^{* * *}$ & .02 \\
\hline Intercept (I) & $2.37^{* * *}$ & .02 & $2.19^{* * *}$ & .02 & $2.03 * *$ & .03 & $2.25 * *$ & .03 \\
\hline Gender × I & & & $0.37^{* * *}$ & .04 & $0.34^{* * *}$ & .04 & $0.30 * *$ & .03 \\
\hline $\mathrm{HS} \times \mathrm{I}$ & & & & & $0.45^{* *}$ & .04 & $0.13 * *$ & .05 \\
\hline $\mathrm{GY} \times \mathrm{I}$ & & & & & 0.07 & .04 & 0.03 & .04 \\
\hline Family values $\times$ I & & & & & & & $0.18^{* * *}$ & .02 \\
\hline Classroom values $\times$ I & & & & & & & $0.23 * *$ & .03 \\
\hline Teacher enthusiasm $\times I$ & & & & & & & 0.02 & .03 \\
\hline Linear slope (LS) & $0.21 * *$ & .01 & $0.23^{* * *}$ & .01 & $0.24^{* *}$ & .01 & $0.14 * *$ & .07 \\
\hline Gender $\times$ LS & & & $0.05^{* * *}$ & .01 & $0.04 * *$ & .01 & $0.03 *$ & .01 \\
\hline $\mathrm{HS} \times \mathrm{LS}$ & & & & & $0.04 *$ & .02 & 0.03 & .02 \\
\hline GY × LS & & & & & 0.01 & .02 & 0.02 & .02 \\
\hline Family values $\times$ LS & & & & & & & 0.01 & .01 \\
\hline Classroom values $\times$ LS & & & & & & & 0.02 & .01 \\
\hline Teacher enthusiasm $\times$ LS & & & & & & & 0.01 & .01 \\
\hline Quad. slope (QS) & $0.08 * *$ & .00 & $0.08^{* * *}$ & .01 & $0.10 * *$ & .01 & $0.07 * *$ & .01 \\
\hline Gender × QS & & & 0.00 & .01 & 0.01 & .01 & 0.01 & .01 \\
\hline $\mathrm{HS} \times \mathrm{QS}$ & & & & & $0.04 * *$ & .01 & $0.04^{* * *}$ & .01 \\
\hline $\mathrm{GY} \times \mathrm{QS}$ & & & & & 0.02 & .01 & 0.01 & .01 \\
\hline Family values $\times$ QS & & & & & & & 0.01 & .01 \\
\hline Classroom values $\times$ QS & & & & & & & 0.00 & .01 \\
\hline Teacher enthusiasm $\times$ QS & & & & & & & 0.01 & .01 \\
\hline \multicolumn{9}{|l|}{ Random effects } \\
\hline Between: Intercept & $0.542^{* * *}$ & & $0.506^{* * *}$ & & $0.468^{* *}$ & & $0.406^{* * *}$ & \\
\hline Between: Linear slope & $0.036^{* * *}$ & & $0.035^{* * *}$ & & $0.034^{* *}$ & & $0.028 * *$ & \\
\hline Between: Quad. slope & $0.003^{*}$ & & $0.003 *$ & & $0.003^{*}$ & & $0.005^{*}$ & \\
\hline Within & $0.350^{\mathrm{a}}$ & & $0.350^{\mathrm{a}}$ & & $0.351^{\mathrm{a}}$ & & $0.335^{\mathrm{a}}$ & \\
\hline
\end{tabular}

Note. Family values, classroom values, and teacher enthusiasm scores were added as time varying covariates at level 1 (group mean centered, without random effects) and at the person level 2 , averaged across time and then $z$ standardized.

HS Hauptschule (lowest track; coded 0 does not attend Hauptschule, 1 attends Hauptschule); GY Gymnasium (highest track; coded 0 does not attend Gymnasium, 1 attends Gymnasium). Realschule (medium track) represents the reference category.

${ }^{\mathrm{a}}$ For this statistic, there is no significance test available.

$* p \leq .05 ; * * p<.01$. 
Figure 1) confirmed that gender differences in interest were evident across the entire time period. In addition, there was a significant positive Gender $\times$ Linear Growth interaction, implying that the decline was steeper for girls than for boys in grade 7 . However, gender did not significantly predict the quadratic shape of the growth function.

\section{Ability Group}

Next, we added school track as a predictor of the growth parameters of mathematics interest (Gender and School Track Model, third column in Table 3). Two dummy variables were entered to model the effect of school track (Gymnasium, Hauptschule). Thus, Realschule served as the reference category. The effects of gender remained unaffected by the introduction of these dummy variables. There was a significant positive coefficient for Hauptschule (.45) and a nonsignificant coefficient for Gymnasium (.07) on the intercept. This indicated that students from the Hauptschule reported higher levels of mathematics interest in grade 7 than students from the Gymnasium and Realschule, who in turn did not significantly differ. Further, Hauptschule membership coincided with a weaker linear decline in interest at grade 7 (coefficient of .04 for the linear slope), and, more importantly, a wider curvature (negative coefficient of -.04 for the quadratic growth parameter). This finding implies a more favorable interest trajectory for students attending Hauptschule, compared with students from the other two

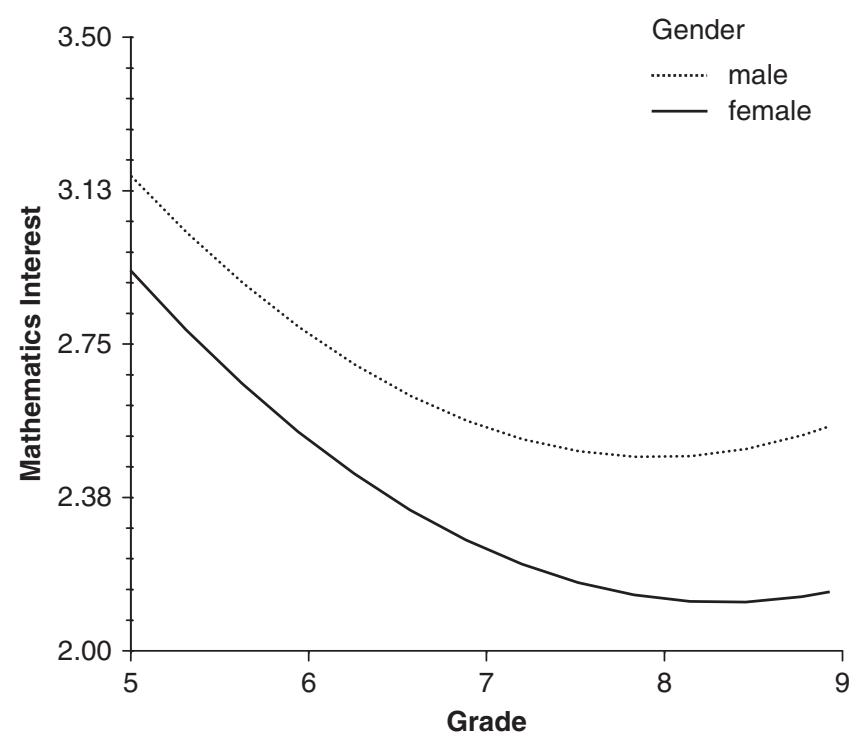

FIGURE 1 Development of mathematics interest as a function of gender. 
school tracks. The nonsignificant coefficients of Gymnasium on linear and quadratic growth indicated that students from Gymnasium versus Realschule did not differ in the shape of their interest growth functions.

A visual inspection of the three latent growth curves based on these analyses (see Figure 2) revealed that Hauptschule students started out with lower levels of interest in grade 5, but then followed a growth trajectory that was only weakly curved, whereas students from the Realschule and Gymnasium initially had more elevated levels of interest, but then followed strongly curved trajectories with considerable declines particularly during grades 5-7.

\section{Family Values, Classroom Values, and Teacher Enthusiasm}

Finally, family values, classroom values, and teacher enthusiasm were added to the analysis, both at level 1 as time-varying covariates (group-mean centered), and as predictors of the growth parameters at level 2, averaged across the five time points (Full Model, fourth column in Table 3). Each of the three value variables proved to be positively related to interest within students. That is, relative to their individual mean interest levels, the individual students' interest scores tended to be higher in years when his or her parents and classmates expressed higher levels of mathematics values, and when the mathematics teacher expressed more enthusiasm. The pattern of growth parameters was unaffected by the introduction of values as time-varying

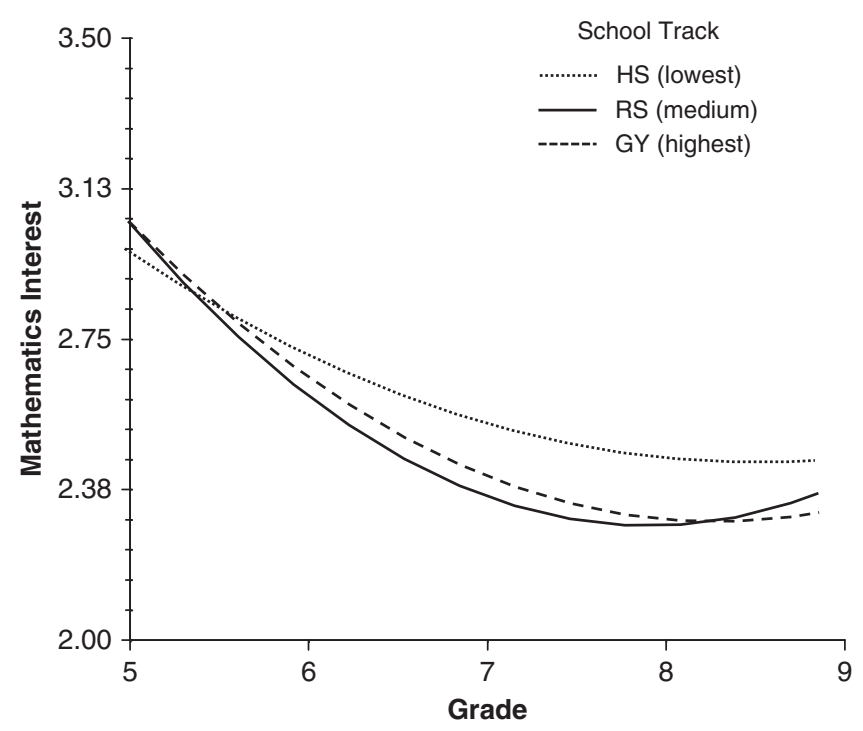

FIGURE 2 Development of mathematics interest as a function of school track. 
covariates, implying that the findings on interest loss were robust when controlling for change of contexts. Above and beyond these within-student effects of socializers' values, time-aggregated family and classroom values significantly positively related to levels of interest in grade 7 (coefficients of $.18 / .23$ for family/classroom values on the intercept). Time-aggregated teacher enthusiasm was unrelated to the intercept. Finally, family and classroom values as well as teacher enthusiasm proved unrelated to the other growth parameters of the interest trajectories.

\section{DISCUSSION}

The purpose of this study was threefold: (1) to describe developmental changes in students' interest in the domain of mathematics from grades 5 to 9 , (2) to explore related effects of gender and school track on the level and shape of mathematics interest trajectories, and (3) to examine whether family values for mathematics, classroom values for mathematics, and teacher enthusiasm were related to interest levels within students, as well as to level and shape of developmental trajectories of interest across students. The study was based on a large-scale German longitudinal data set of 3,193 students from grades 5 through 9 . We found curvilinear developmental trajectories indicating a loss of mathematics interest across adolescence and consistent gender effects on the level of mathematics interest to the advantage of boys. Because this study was located in a cultural and institutional background that differed from previous studies, our findings support the generality of these processes also identified in previous research. In addition, ability grouping as implied by the German school system proved to be related to interest development, with students of low-achievement groups (Haupschule) experiencing more favorable interest trajectories than students in high-achieving groups (Realschule and Gymnasium). Finally, our study extends existing knowledge regarding the importance of socializers for adolescents' interest development by documenting positive relationships between parents' and classmates' mathematics values as well as teacher's enthusiasm with students' interest in mathematics.

\section{Shape of Interest Trajectories}

In line with our expectations, we found there was a considerable loss of interest between grades 5 and 7 , which then plateaued in grades 8 and 9. This loss of interest was also found when controlling for changes of students' contexts over time. Apart from the large proportions of the variability in interest scores occurring within students across occasions, the variation between students was predominantly due to overall level differences, whereas students varied comparatively little in the shapes of their curvilinear interest 
trajectories. Comparing and contrasting these results with findings from United States and Australian research (Eccles et al., 1983; Fredricks \& Eccles, 2002; Jacobs et al., 2002; Watt, 2004), it is interesting to see that this decline is evident even though the students in our sample did not experience any school transition during the observed period of time. Basic changes regarding school size and organizational atmosphere thus can be excluded as reasons for interest losses in our sample. Still, even within the same schools, instructional structures and climates in terms of task complexities, competition, grouping practices, evaluation techniques, and motivational strategies may change over the years (Jacobs et al., 2002). One indicator of potential change in instructional quality across the years in the present sample may be reflected in the decreasing levels of students' perceptions of their mathematics teachers' enthusiasm in later grades.

\section{Effects of Gender}

Regarding gender effects on interest levels, we found as we had expected consistent differences for girls and boys. That is, girls already had lower interest in mathematics in grade 5, and gender differences continued to exist through grades 6-9. Further, our latent growth curve analyses revealed no gender differences in the quadratic growth parameter. This means that girls' and boys' interest developed along equally shaped trajectories, but they followed along these trajectories at displaced points of time and at different levels. Also in line with our expectations, no gender intensification in terms of more weakly curved quadratic trajectories among the boys could be found. However, one may draw inferences about gender intensification from the effect of gender on the linear slope of the growth trajectory at a given point of time. In that respect, we could identify a phase of gender intensification in grade 7 (as indicated by the statistically significant effect of gender on the linear slope parameter in our data), which seemed to be a phase of steeper linear slope of the interest loss trajectory for girls compared with boys. At this point, the decline of boys' interest tended to stabilize and level out, whereas girls still suffered from rather serious interest losses. Later in adolescence, however, interest scores of both girls and boys plateaued and the gender gap did not widen any more. ${ }^{2}$ This pattern of findings may be useful to interpret the fact that previous findings have been equivocal in their evidence to support gender intensification, some studies finding support for that hypothesis (Eccles, 1987; Hill \& Lynch, 1983) and others not (Fredricks \& Eccles, 2002; Jacobs et al., 2002; Watt, 2004). It seems that it depends on the point of time at which the effect of gender on the linear slopes of interest declines is

\footnotetext{
${ }^{2}$ Providing statistical confirmation for this claim, a reanalysis of the data using an alternative coding of time with the reference category set to the last occasion (grade 9) revealed that the Gender $\times$ Linear Slope interaction was no longer significant at this point in time.
} 
inspected whether gender intensification or gender stabilization may be inferred.

\section{Ability Grouping and Interest Development}

Our data clearly revealed more favorable interest trajectories for students attending the low-achievement track (Hauptschule), compared with the medium- and high-achievement tracks. For the latter two tracks, interest trajectories did not differ. As such, students from the Hauptschule seemed to start out with slightly lower levels of mathematics interest in grade 5, but then followed a comparatively favorable growth trajectory with a weak curvature. In contrast, students from the Realschule and Gymnasium initially showed higher levels of interest, but then suffered from more substantial declines during grades $5-7$ that only marginally recovered in grades 8 and 9 .

These findings are in line with existing evidence on the positive effects of being placed into low achievement groups, and negative effects of being placed into high achievement groups, as reported for academic self-concepts, but also academic interests (Marsh \& Hau, 2003; Trautwein et al., 2006). One reason for the less negative development at the Hauptschule could be that the curriculum in this track is not as demanding as in the higher tracks, implying that students can develop a more positive attitude toward mathematics. Another reason might lie in interindividual comparison processes. It is likely that low-achieving students experience predominantly unfavorable upward social comparisons during elementary school, which contribute to their comparatively low levels of interest in grade 5 (i.e., the first year after primary school in Germany). After being placed into a homogeneous lowachieving ability group (Hauptschule), quite some of these students would seem to profit from favorable downward comparisons-resulting in a comparatively weak average loss of interest during adolescence in this school track. Conversely, students placed in higher-achieving tracks probably change from initially favorable to more unfavorable social comparisons after the transition from elementary to secondary school, resulting in relatively high initial levels of reported interest and serious declines afterwards.

Overall, the present study corroborates recent evidence for the BFLPE for academic interest. In addition this is the first study to provide longitudinal evidence that ability grouping is related to the development of mathematics interest. More specifically, our data show that ability grouping not only has effects upon, or directly following, the placement of students into homogeneous ability groups, but that tracking continues to have effects for several years beyond. In Germany, many parents are reluctant to let their children attend Hauptschule, understanding that it provides lower educational qualification, entailing fewer opportunities for occupational careers. However, our findings corroborate the notion that adolescents may profit rather than 
suffer from being placed in Hauptschule in terms of their affective development (i.e., in terms of their academic interests).

\section{Links to Socializers' Values}

As expected, family and classroom values as well as teacher enthusiasm positively related to students' levels of interest during grades 5-9. Above and beyond within-student effects on interest, exposure to high parental and classroom values over this entire developmental period was associated with overall higher interest levels across students. This supports the notion that parents and teachers act as role models and transmit their expressed values to the adolescents. Likewise, classmates do seem to influence each other in their valuing for, and resulting interest in, specific academic domains. However, family, classroom, and teacher values were unrelated to the change trajectory. That is, there was no deceleration of interest declines based on socially transmitted values. Overall, our data imply that family-, peer-, and teacher-conveyed values play an important role for the formation of interest and for the level at which it develops, but not so much for its change during adolescence.

\section{Limitations and Directions for Future Research}

The present study has limitations that can be used to suggest directions for future research on interest development and its relationship with contextual factors. First, as in most other studies examining growth of student characteristics over time, the fact that students are hierarchically nested within classes had to be neglected in the present analysis due to changing class composition over time. This may have led to an underestimation of standard errors, implying that small effects on growth parameters should be interpreted cautiously.

In addition, in the present study, socializers' attitudes were modeled as time-varying predictors at level 1 and as time-invariant variables at the person level by incorporating average scores for these variables across time. Above and beyond this mean value, a cumulative value (e.g., in terms of multiplicatively rather than additively combined scores across the years) might be relevant, implying, for example, that low values transmitted to students in just 1 year undermine the effects of high values in other years (see also Smith, Jussim, \& Eccles, 1999, for similar considerations on effects of teacher expectations). Also, upward or downward trends may be predictive of adolescents' interest development. Differential trends of valuerelated context variables over time were not taken into account in this study. Rather, our approach served to provide a broad picture concerning which contextual factors played a role for students' interest development in mathematics during adolescence. Future research could use more fine-grained 
approaches to analyze the processes by which socializers' values impact across time. Specifically, addressing the effects of systematic changes in contextual factors (such as moving from high-value to low-value classes, or changing from an unenthusiastic teacher to an enthusiastic one) could be one productive approach.

Finally, the present conceptualization of family values for mathematics did not take parent or student gender into account. Previous research has shown that mothers and fathers can differ in their subjective values regarding specific domains (e.g., Eccles et al., 1993). Such differences would have been masked in our approach, which asked for general family values. Research has also shown that parents tend to hold different values for their sons versus their daughters-for example, the subject of mathematics might be considered more relevant for their son's aspired careers than for their daughter's (e.g., Frome \& Eccles, 1998; Jacobs, Chhin, \& Bleeker, 2006). These potential differences were not addressed in our scale on family values either. However, the scores on our scale were consistently related to students' levels of interest in mathematics, corroborating their relevance.

\section{Conclusion}

The present findings describing downward developmental trajectories of mathematics interest in adolescence are largely in line with the existing longitudinal findings regarding mathematics interest losses in German selected schools (Köller et al., 2001), and decreasing mathematics values among American and Australian students (Brush, 1985; Fredricks \& Eccles, 2002; Jacobs et al., 2002; Watt, 2004). This suggests that interest losses seem to be a robust process that occurs across different cultures and different educational systems. Developmental change in mathematics interest seems to happen at different levels (higher for students from high-value families and classrooms and with enthusiastic teachers), at different points in time (later for girls), and to different degrees (less for students in lower school tracks). However, our study also clearly showed that variability between students pertained to the level but not the shape of the growth trajectories. This suggests that adolescent interest development seems to unfold along similar trajectories for the majority of students. Given that the trajectories of interest loss were similarly shaped, it could be argued that declines in interest are normative adolescent phenomena. Once triggered, considerable interest declines seem to occur and to follow similar lines. This loss of interest may be brought about by curricular changes or explained by factors inherent in age-related changes involving more realistic judgments of one's capacities, paired with the increased complexity of academic content, and consequent lower task intrinsic attractiveness (Hidi, 2000; Zimmerman \& Kitsantas, 1999).

In conclusion, our data may be interpreted in terms of reassuring news for parents and teachers: Even though no chance should be passed up to foster 
students' interests in academic fields, parents and teachers need not blame themselves for normative interest losses during adolescence. Curvilinear interest trajectories also provide hints that interests may recover at later ages. Educators should engage in helping adolescents to identify their individually preferred fields of interest and supporting them during the agitated period of adolescence, without being discouraged by seemingly low levels of motivation that may be typical for this developmental stage (see Baumert \& Köller, 1998, for a similar argument). In so doing, great emphasis should be placed on avoiding gender stereotyping since girls still substantially lag behind boys in their interest in mathematics.

\section{ACKNOWLEDGMENTS}

This research was supported by a grant from the German Research Foundation (PE 320/11-3, PE 320/11-4, PE 320/11-5) awarded to the third author. We acknowledge the helpful comments of Dr. Ulrike Nett on previous versions of this paper.

\section{APPENDIX A}

TABLE A1

Items Used in the Study to Assess Interest

I am interested in mathematics

I like to read books and solve brainteasers related to mathematics

Doing mathematics is one of my favorite activities

I often find the things we deal with in mathematics really exciting

After a math class, I am often curious about what we are going to do in the next lesson

I would like to find out much more about some of the things we deal with in our mathematics class

\section{REFERENCES}

Aiken, L. S., \& West, S. G. (1991). Multiple regression: Testing and interpreting interactions. Newbury Park, CA: Sage.

Aleamoni, L. M. (1999). Student rating myths versus research facts from 1924 to 1998. Journal of Personnel Evaluation in Education, 13, 153166.

Allison, P. D. (2001). Missing data. Thousands Oaks, CA: Sage.

Baumert, J., \& Koller, O. (1998). Interest research in secondary level I: An overview. In L. Hoffmann, A. Krapp, K. A. Renninger, \& J. Baumert (Eds.), Interest and learning (pp. 241 256). Kiel: IPN.

Baumert, J., \& Schnabel, K. (1998). Learning math in school: Does interest really matter. In L. Hoffmann, A. Krapp, K. A. Renninger, \& J. Baumert (Eds.), Interest and learning (pp. 327 336). Kiel: IPN.

Bergin, D. A. (1999). Influences on classroom interest. Educational Psychologist, 34, 8798. 
Biesanz, J. C., Deeb Sossa, N., Papadakis, A. A., Bollen, K. A., \& Curran, P. J. (2004). The role of coding time in estimating and interpreting growth curve models. Psychological Methods, 9 , 3052.

Brigham, F. J., Scruggs, T. E., \& Mastropieri, M. A. (1992). Teacher enthusiasm in learning dis abilities classrooms: Effects on learning and behavior. Learning Disabilities Research and Prac tice, 7, 6873 .

Brown, B. B. (1990). Peer groups and peer culture. In S. S. Feldman \& G. R. Elliott (Eds.), At the threshold: The developing adolescent (pp. 171 196). Cambridge, MA: Harvard University Press.

Brush, L. R. (1985). Cognitive and affective determinants of course preferences and plans. In S. F. Chipman, L. R. Brush, \& D. M. Wilson (Eds.), Women and mathematics: Balancing the equation (pp. 123 150). Hillsdale, NJ: Erlbaum.

Cohen, J. (1978). Partialed products are interactions; partialed vectors are curve components. Psychological Bulletin, 85, 858866.

De Jong, R., \& Westerhof, K. J. (2001). The quality of student ratings of teacher behaviour. Learning Environments Research, 4, 5185.

Eccles, J. S. (1987). Gender roles and women's achievement related decisions. Psychology of Women Quarterly, 11, 135172.

Eccles, J. S., Adler, T. F., Futtermann, R., Goff, S. B., Kaczala, C. M., Meece, J. L., et al. (1983). Expectancies, values and academic behaviors. In J. T. Spence (Ed.), Achievement and achieve ment motives: Psychological and sociological approaches (pp. 75 145). San Francisco: Freeman.

Eccles, J. S., Adler, T. F., \& Kaczala, C. M. (1982). Socialization of achievement attitudes and beliefs: Parental influences. Child Development, 53, 310321.

Eccles, J. S., Adler, T. F., \& Meece, J. L. (1984). Sex differences in achievement: A test of alternate theories. Journal of Personality and Social Psychology, 46, 2643.

Eccles, J. S., Arberton, A., Miller Buchanan, C., Jacobs, J. E., Flanagan, C., Harold, R., et al. (1993). School and family effects on the ontogeny of children's interests, self perceptions, and ac tivity choices. In J. E. Jacobs (Ed.), Nebraska Symposium on Motivation, 1992: Developmental perspectives on motivation (pp. 145 208). Lincoln, NE: University of Nebraska Press.

Eccles, J. S., Buchanan, C. M., Flanagan, C., Fuligni, A., Midgley, C., \& Lee, D. (1991). Control versus autonomy during early adolescence. Journal of Social Issues, 47, 5368.

Eccles, J. S., \& Midgley, C. (1989). Stage/environment fit: Developmentally appropriate class rooms for early adolescents. In R. A. C. Ames (Ed.), Research on motivation in education (Vol.3, pp. 139 181). New York: Academic Press.

Eccles, J. S., Midgley, C., Miller Buchanan, C., Reuman, D., Flanagan, C., \& MacIver, D. (1993). Development during adolescence: The impact of stage environment fit on young adolescents' task values and expectancy related beliefs. American Psychologist, 48, 90101.

Eccles, J. S., Wigfield, A., Flanagan, C., Miller, C., Reuman, D., \& Yee, D. (1989). Self concept, domain values, and self esteem: Relations and changes at early adolescence. Journal of Per sonality, 57, 283310.

Eccles, J. S., Wigfield, A., Harold, R. D., \& Blumenfeld, P. B. (1993). Age and gender differences in children's self and task perceptions during elementary school. Child Development, 64, 830847.

Flink, C., Boggiano, A. K., \& Barrett, M. (1990). Controlling teaching strategies: Undermining children's self determination and performance. Journal of Personality and Social Psychology, 59, 916924.

Fredricks, J. A., \& Eccles, J. (2002). Children's competence and value beliefs from childhood through adolescence: Growth trajectories in two male sex typed domains. Developmental Psychology, 38, 519533.

Frenzel, A. C., Goetz, T., Ludtke, O., Pekrun, R., \& Sutton, R. E. (2009). Emotional transmission in the classroom: Exploring the relationship between teacher and student enjoyment. Journal of Educational Psychology, 101, 705716. 
Frenzel, A. C., Pekrun, R., \& Goetz, T. (2007a). Girls and mathematics a "hopeless" issue? A control value approach to gender differences in emotions towards mathematics. European Journal of Psychology of Education, 22, 497514.

Frenzel, A. C., Pekrun, R., \& Goetz, T. (2007b). Perceived learning environment and students emotional experiences: A multilevel analysis of mathematics classrooms. Learning and Instruction, 17, 478493.

Frome, P. M., \& Eccles, J. S. (1998). Parents' influence on children's achievement related per ceptions. Journal of Personality and Social Psychology, 74, 435452.

Galambos, N. L., Almeida, D. M., \& Peterson, A. C. (1990). Masculinity, femininity, and sex role attitudes in early adolescence: Exploring gender intensification. Child Development, 61, 1905 1914.

Goetz, T., Pekrun, R., Zirngibl, A., Jullien, S., Kleine, M., vom Hofe, R., et al. (2004). Leistung und emotionales Erleben im Fach Mathematik: Langsschnittliche Mehrebenenanalysen [Aca demic Achievement and Emotions in Mathematics: A Longitudinal Multilevel Analysis Perspective]. Zeitschrift für Pädagogische Psychologie, 18, 201212.

Gonzalez DeHass, A. R., Willems, P. P., \& Holbein, M. F. D. (2005). Examining the relationship between parental involvement and student motivation. Educational Psychology Review, 17, 66123.

Hidi, S. (1990). Interest and its contribution as a mental resource for learning. Review of Edu cational Research, 60, 549571.

Hidi, S. (2000). An interest researcher's perspective on the effects of extrinsic and intrinsic factors on motivation. In B. Sansone \& J. M. Harackiewitz (Eds.), Intrinsic and extrinsic motivation: The search for optimum motivation and performance (pp. 309 330). New York: Academic Press.

Hidi, S., \& Harackiewicz, J. M. (2000). Motivating the academically unmotivated: A critical issue for the 21st century. Review of Educational Research, 70, 151179.

Hidi, S., \& Renninger, K. A. (2006). The four phase model of interest development. Educational Psychologist, 41, 111127.

Hill, J. P., \& Lynch, M. E. (1983). The intensification of gender related role expectations during early adolescence. In J. Brooks Gunn \& A. C. Peterson (Eds.), Girls at puberty (pp. 201 228). New York: Plenum.

Hoffmann, L., Krapp, A., Renninger, K. A., \& Baumert, J. (1998). Interest and learning: Proceedings of the Seeon Conference on Interest and Gender. Kiel: IPN.

Hyde, J. S., Fennema, E., Ryan, M., Frost, L. A., \& Hopp, C. (1990). Gender comparisons of mathematics attitudes and affect: A meta analysis. Psychology of Women Quarterly, 14, 299324.

Jackson, D. L., Teal, C. R., Raines, S. J., Nansel, T. R., Force, R. C., \& Burdsal, C. A. (1999). The dimensions of students' perceptions of teaching effectiveness. Educational and Psychological Measurement, 59, 580596.

Jacobs, J. E., Chhin, C. S., \& Bleeker, M. M. (2006). Enduring links: Parents' expectations and their young adult children's gender typed occupational choices. Educational Research and Evalu ation, 12, 395407.

Jacobs, J. E., Davis Kean, P., Bleeker, M. M., Eccles, J. S., \& Malanchuk, O. (2005). 'I can, but I don't want to': The impact of parents, interests, and activities on gender differences in math. In A. M. Gallagher \& J. C. Kaufman (Eds.), Gender differences in mathematics: An integrative psychological approach (pp. 246 263). New York: Cambridge University Press.

Jacobs, J. E., \& Eccles, J. S. (2000). Parents, task values, and real life achievement related choices. In C. Sansone \& J. M. Harackiewicz (Eds.), Intrinsic and extrinsic motivation: The search for optimal motivation and performance (pp. 405 439). San Diego, CA: Academic Press.

Jacobs, J. E., Lanza, S., Osgood, D. W., Eccles, J. S., \& Wigfield, A. (2002). Changes in children's self competence and values: Gender and domain differences across grades one through twelve. Child Development, 73, 509527. 
Jullien, S. (2006). Elterliches Engagement und Lern \& Leistungsemotionen [Parental Engagement and Achievement Emotions]. Munchen: Herbert Utz.

Kessels, U., \& Hannover, B. (2007). How the image of math and science affects the development of academic interests. In M. Prenzel (Ed.), Studies on the educational quality of schools. The final report on the DFG priority programme (pp. 283 297). Munster, Germany: Waxmann.

Kindermann, T. A. (1993). Natural peer groups as contexts for individual development: The case of children's motivation in school. Developmental Psychology, 26, 970977.

Koller, O., Baumert, J., \& Schnabel, K. (2001). Does interest matter? The relationship between academic interest and achievement in mathematics. Journal for Research in Mathematics Education, 32, 448470.

Krapp, A. (2000). Interest and human development during adolescence: An educational psy chological approach. In J. Heckhausen (Ed.), Motivational psychology of human development (pp. 109 128). Oxford, UK: Elsevier.

Larson, R. W., \& Richards, M. H. (1991). Daily companionship in late childhood and early adolescence: Changing developmental contexts. Child Development, 62, 284300.

LeTendre, G. K., Hofer, B. K., \& Shimizu, H. (2003). What is tracking? Cultural expectations in the United States, Germany, and Japan. American Educational Research Journal, 40, 4389.

Lichtenfeld, S., Frenzel, A. C., \& Pekrun, R. (2007). Gender differences in students' emotions in elementary school. Paper presented at the 12th Biennial Conference of the European Associ ation for Research on Learning and Instruction, Budapest, Hungary.

Lucas, S. R. (1999). Tracking inequality: Stratification and mobility in American high schools. New York: Teachers College Press.

Ludtke, O., Trautwein, U., Kunter, M., \& Baumert, J. (2006). Reliability and agreement of student ratings of the classroom environment a reanalysis of TIMSS data. Learning Environments Research, 9, 215230.

Marchant, G. J., Paulson, S. E., \& Rothlisberg, B. A. (2001). Relations of middle school students' perceptions of family and school contexts with academic achievement. Psychology in the Schools, 38, 505519.

Marsh, H. W. (1982). SEEQ: A reliable, valid, and useful instrument for collecting students' evaluations of university teaching. British Journal of Educational Psychology, 52, 7795.

Marsh, H. W. (1987). The big fish little pond effect on academic self concept. Journal of Educa tional Psychology, 79, 280295.

Marsh, H. W. (1991). The failure of high ability schools to deliver academic benefits: The im portance of academic self concept and educational aspirations. American Educational Research Journal, 28, 445480.

Marsh, H. W., \& Hau, K. T. (2003). Big fish little pond effect on academic self concept. American Psychologist, 58, 364376.

McKinney, C. W., Robertson, C. W., Gilmore, A. C., Ford, M. J., \& Larkins, A. G. (1984). Some effects of three levels of teacher enthusiasm on student achievement and evaluation of teacher effectiveness. Journal of Instructional Psychology, 11, 119124.

Nagy, G., Trautwein, U., Baumert, J., Koller, O., \& Garrett, J. (2006). Gender and course selection in upper secondary education: Effects of academic self concept and intrinsic value. Educa tional Research and Evaluation, 12, 323345.

OECD. (2004). Learning for tomorrow's world: First results from PISA 2003. Paris, France: OECD Publications.

Patrick, B. C., Hisley, J., Kempler, T., \& College, G. (2000). “What's everybody so excited about?": The effects of teacher enthusiasm on student intrinsic motivation and vitality. Journal of Experimental Education, 68, 15211558.

Pekrun, R. (2000). A social cognitive, control value theory of achievement emotions. In J. Heck hausen (Ed.), Motivational psychology of human development (pp. 143 163). Oxford, UK: Elsevier. 
Pekrun, R., Goetz, T., \& Frenzel, A. C. (2005). Achievement Emotions Questionnaire Mathematics (AEQ M) User's manual. Munich, Germany: Department of Psychology, University of Munich.

Pekrun, R., vom Hofe, R., Blum, W., Frenzel, A. C., Goetz, T., \& Wartha, S. (2007). Development of mathematical competencies in adolescence: The PALMA longitudinal study. In M. Prenzel (Ed.), Studies on the educational quality of schools. The final report on the DFG priority programme (pp. 17 37). Munster, Germany: Waxmann.

Pekrun, R., vom Hofe, R., Blum, W., Goetz, T., Frenzel, A. C., Jullien, S., et al. (2006). Project for the analysis of learning mathematics. Unpublished research report, University of Munich, Munich, Germany.

Raudenbush, S. W., \& Bryk, A. S. (2002). Hierarchical linear models. Applications and data analysis methods (2nd ed.). Thousand Oaks, CA: Sage.

Raudenbush, S. W., Bryk, A., \& Congdon, R. (2007). Hierarchical linear and nonlinear modeling (HLM) (Version 6.04) [Computer Software]. Lincolnwood, IL: Scientific Software International.

Renninger, K. A. (2000). Individual interest and its implications for understanding intrinsic motivation. In B. Sansone \& J. M. Harackiewitz (Eds.), Intrinsic and extrinsic motivation: The search for optimal motivation and performance (pp. 375 407). New York: Academic Press.

Schafer, J. L., \& Graham, J. W. (2002). Missing data: Our view of the state of the art. Psychological Methods, 7, 147177.

Schiefele, U. (1991). Interest, learning, and motivation. Educational Psychologist, 26, 299323.

Schiefele, U. (2001). The role of interest in motivation and learning. In J. M. Collis \& S. Messick (Eds.), Intelligence and personality: Bridging the gap in theory and measurement (pp. 163 194). Mahwah, NJ: Erlbaum.

Schiefele, U., Krapp, A., Wild, K. P., \& Winteler, A. (1993). Der “Fragebogen zum Stud ieninteresse" (FSI) [The study interest questionnaire (SIQ)]. Diagnostica, 39, 335351.

Schiefele, U., Krapp, A., \& Winteler, A. (1992). Interest as a predictor of academic achievement: A meta analysis of research. In K. A. Renninger, S. Hidi, \& A. Krapp (Eds.), The role of interest in learning and development (pp. 183 212). Hillsdale, NJ: Erlbaum.

Schnepf, S. V. (2003). Inequalities in secondary school attendance in Germany. Southampton, UK: Southampton Statistical Sciences Research Institute.

Smith, A. E., Jussim, L., \& Eccles, J. (1999). Do self fulfilling prophecies accumulate, dissipitate, or remain stable over time? Journal of Personality and Social Psychology, 77, 548565.

Todt, E., \& Schreiber, S. (1998). Development of interest. In L. Hoffmann, A. Krapp, \& J. Baumert (Eds.), Interest and learning (pp. 25 40). Kiel: IPN.

Trautwein, U., Ludtke, O., Marsh, H. W., Koller, O., \& Baumert, J. (2006). Tracking, grading, and student motivation: Using group composition and status to predict self concept and interest in ninth grade mathematics. Journal of Educational Psychology, 98, 788806.

Turner, J., Midgley, C., Meyer, D., Gheen, M., Anderman, E., Kang, Y., et al. (2002). The classroom environment and students' reports of avoidance strategies in mathematics: A multimethod study. Journal of Educational Psychology, 94, 88106.

Watt, H. M. G. (2004). Development of adolescents' self perceptions, values, and task perceptions according to gender and domain in 7th through 11th grade Australian students. Child De velopment, 75, 15561574.

Watt, H. M. G., Richardson, P. W., \& Pietsch, J. (2009). Choosing to teach in the "STEM" dis ciplines: Characteristics and motivations of science, technology, and mathematics teachers from Australia and the United States. In A. Selkirk \& M. Tichenor (Eds.), Teacher education: Policy, practice and research (pp. 285 309). New York: Nova Science Publishers.

Whitbeck, L. B., \& Gecas, V. (1988). Value attributions and value transmission between parents and children. Journal of Marriage and the Family, 50, 829840.

Wigfield, A., \& Eccles, J. (1992). The development of achievement task values: A theoretical analysis. Developmental Review, 12, 265310. 
Wigfield, A., Eccles, J., Mac Iver, D., Reuman, D., \& Midgley, C. (1991). Transition to early adolescence: Changes in children's domain specific self perceptions and general self esteem across the transition to junior high school. Developmental Psychology, 27, 552565.

Wigfield, A., Eccles, J., Yoon, K. S., Harold, R. D., Arbreton, A., \& Freedman Doan, K. (1997). Change in children's competence beliefs and subjective task values across the elementary schools years: A three year study. Journal of Educational Psychology, 89, 451469.

Zeidner, M. (1998). The big fish little pond effect for academic self concept, test anxiety, and school grades in gifted children. Contemporary Educational Psychology, 24, 305329.

Zimmerman, B. J., \& Kitsantas, A. (1999). Acquiring writing revision skills: Shifting from process to outcome self regulatory goals. Journal of Educational Psychology, 91, 110. 